\title{
Corpo e Identidade - medicina e imaginação no thriller hollywoodiano contemporâneo - Uma análise de A Outra Face (Face/Off), de John Woo Lécio Augusto Ramos"
}

\section{RESUMO}

Este trabalho examina uma das formas da representaçāo da Medicina moderna no cinema de ficção hollywoodiano e, em particular, o questionamento da identidade que as tecnologias médicas propiciam, através de Face/Off (A outra face), realizado em 1997 por John Woo, mestre chinês do cinema de ação coreografada e violência estilizada. A escolha de Face/Off se deve, em primeiro lugar, a um fascinio um tanto "escandalizado" pela forma como o filme trata a tecnologia médica no interior de um gênero nada realista que é o thriller policial, e, em segundo, por um certo desconforto causado pela exacerbação do questionamento da identidade que o filme promove.

\section{ABSTRACT}

This article examines one of the ways of representation of the modern Medicine in the Hollywood cinema and, specifically, the discussion of the identity promoted by the medical technologies, taking by sample the movie Face/Off, directed in 1997 by John Woo. Chinese master of the movies with acrobatic action and stylized violence. The choice of Face/Off is due, in first place, to a fascination by the form as the film treats the medical technology inside a gender non realist as the criminal thriller, and, in second place, for a certain discomfort caused by the exacerbation of the discussion of the identity that the film promotes.

\footnotetext{
* Professor do Departamento de Cinema e Video da UFF, mestrando do Programa de Pós. Graduaçāo em Comunicação, Imagem e Informação da mesma universidade. Escreveu vários verbetes para a "Enciclopédia do Cinema Brasileiro" (Sào Paulo: Senac, 2000), organizada por Fernāo Ramos e Luiz Felipe Miranda, além de vários artigos sobre cinema.
} 
A interrogação sobre os vínculos inexoráveis entre cinema e ciência, como sabemos, existe desde antes do cinematógrafo. Gostaria de destacar que o pioneiro das pesquisas que levaram à constituição da tecnologia de representação fotográfica do movimento, o fisiologista francês Etienne-Jules Marey, é considerado também o precursor da Biomecânica, um ramo da Medicina Esportiva e da Educação Física que estuda o corpo humano em movimento e em atividade física. Embora eu venha a fazer menção vez ou outra a estas relações umbilicais entre cinema e medicina, esta não é porém a perspectiva fundamental adotada aqui. Parece-me que ela se aproxima da abordagem de Deborah Lupton (LUPTON, 1994), no sentido de um exame das representações da Medicina na cultura popular e nos meios de comunicação de massa. Segundo ela, nas representações feitas nos meios de comunicação populares, a tecnologia médica é singularizada como a apoteose da magia médica, especialmente nos dramas seriados produzidos dos Estados Unidos, como $E R$, com seus sofisticados equipamentos de última geração, suas luzes piscantes, os "blips" intermitentes dos monitores dos pacientes, que ficam deitados passivamente e estão inteiramente submetidos à figura superhumana dos médicos (p. 53). Contudo, a investigação de Lupton se concentra na questão da doença, que é de fato o aspecto dominante da abordagem da Medicina no cinema. Filmes como Face/Off pertencem a uma certa linhagem (que eu pretendo inventariar) que tratam das aplicações da Medicina em indivíduos saudáveis, mesmo porque se circunscrevem a um ramo específico que é a Cirurgia Plástica. A minha consideração do problema é portanto bastante específica, tocando apenas superficialmente em temas da maior relevância que dizem respeito às representações da Medicina no cinema.

$\mathrm{Na}$ primeira parte, procuro estabelecer algumas associações entre Medicina e cinema, aludindo de passagem às similaridades que presidiram à constituição dos dois campos como área tecnológica. Em seguida, pareceu-me pertinente fazer uma pequena e modesta digressão teórica em torno do tema da dupla identidade na cultura ocidental, para situar os antecedentes de um dos subtemas do argumento de Facel Off, que é a perda da identidade. Abordo finalmente na terceira parte o filme de John Woo, procurando estabelecer uma genealogia da abordagem do cinema do tema da troca cirúrgica de identidade que, se não serviu diretamente de inspiração para o argumento do filme, ao menos dão um quadro sobre as formas de representação destas identidades trocadas adotadas pelo cinema. 
Uma interface crítica e analítica entre Cinema e Medicina, pelo pouco que me foi dado a conhecer, carece ainda de um maior aprofundamento. Há algumas indagações que merecem respostas mais precisas. Em que circunstâncias a Medicina é fundamental para a construção de uma verossimilhança que dá ao gênero "thriller" uma consistência lógica (respeito à ciência)? Por que não obstante. a Medicina não é apresentada nestes filmes dentro de seu quadro histórico e tecnológico real, mas sim de uma forma idealizada, quase utópica? Paara tentar responder a estas e outras interrogações é que este texto foi escrito.

\section{O cinema narrativo e a Medicina: aproximaçōes}

É preciso antes advertir que meu propósito aqui não é fazer um exame minucioso das relações estruturais entre cinema e medicina, no sentido de uma interrogação sobre as analogias entre o cinema como uma técnica de registro e reprodução audiovisual do movimento e da realidade e a tecnologia médica, com especial ênfase nas técnicas de visualização semelhantes ou bem aparentadas entre as duas áras (cf. VIEIRA, 2000). Este trabalho pertence a um outro campo de investigação. que é a representação da Medicina ou de temas a ela associados (doenças, deficiências físicas ou psíquicas) pelo cinema narrativo. Acho necessário no entanto traçar um perfil sucinto desta segunda perspectiva, com o objetivo de situar minha análise particular de Face/Off dentro de um enfoque o mais amplo possível, que explicite bem as relações entre a cultura médica e o cinema.

Embora uma pesquisa mais sistemática sobre a abordagem de temas médicos pelo cinema ainda não tenha sido feita. muitos autores apontam o clássico do horror gótico Frankenstein (1931. James Whale). como uma espécic de matriz da relação entre medicina e cinema. Frankenstein foi por exemplo o ponto de partida de Frankenstein's Footsteps, livro bastante ambicioso do americano Jon Turney sobre a representação da ciência biológica na Literatura, no Cinema e no Jornalismo, mostrando como a representação "familiar" do progresso científico tem influenciado a opinião pública ao longo da história. Para Turney, a história da criatura de Frankentein é o paradigma das ansiedades apocalípticas que marcam a relação do homem com a ciência.

O caráter matricial de Frankenstein para a história da relação entre cinema e medicina foi assumido pela U. S. National Library of Medicine, situada em Rockville Pike. Bethesda, MD, que de 30 de outubro de 1997 a 15 de agosto de 1998 promoveu uma grande exposição 
sobre ele, intitulada Frankenstein - Penetrating The Secrets of Nature. No portal da instituição na Internet (

), acessadamem setembro de 2001, havia uma página bastante interessante sobre esta exposição e sobre a própria criatura de Frankenstein (

onde se ressaltam as suas relações com a história da Medicina (ele é chamado ali de Monstro de Celulóide). De fato, o personagem criado por Mary Shelley só se transformou em ícone popular depois da adaptação para o cinema produzida pela Universal em 1931. Segundo a NLM, a história de Frankenstein, que no livro de Shelley era uma "criatura sensível e articulada", foi "deformada" por Hollywood. Mas da mesma forma que ocorre no livro, o filme foi influenciado por algumas preocupações científicas ou pseudo-científicas de seu tempo, como eugenia, robótica e transplantes cirúrgicos.

Esta última observação, provinda de uma instituição médica preocupada em inserir a Medicina na história da Cultura, introduz a questão da verossimilhança ou do realismo que inavariavelmente é utilizada na avaliação do tratamento dado pelo cinema a temas médicos e científicos. Para além da compreensão do discurso cinematográfico como uma construção imaginária que se apropria de forma particular dos dados da realidade sem um compromisso formal de reproduzi-los objetivamente ${ }^{1}, \mathrm{o}$ cinema tem sido submetido a um escrutínio de fundamentação realista que exige uma correspondência estrita entre representação e realidade. Mas o chamado cinema clássico narrativo, que é a referência que mais de perto me interessa aqui, se esquivou como pôde deste pacto com a ciência, em benefício de uma flexibilidade que assegurou a hegemonia da fantasia sobre a objetividade no interior do discurso cinematográfico. Neste sentido, o questionamento da correção das formas de abordagem da ciência nunca foi uma ameaça para a continuidade do fantasiamento ou o falseamento da realidade perpetrada pelo cinema narrativo.

No espaço de tempo que separa Frankenstein e Face/Off, além de um refinamento nas convenções relativas ao realismo e ao verossímil, deve ser destacada a extraordinária evolução da tecnologia cinematográfica, em especial das técnicas de efeitos especiais. As novas tecnologias digitais revolucionaram a forma como o cinema narrativo passou a abordar a Medicina. À proporção que os efeitos especiais relacionados ao corpo humano foram se aperfeiçoando, o ato cirúrgico pôde ser apresentado de forma mais detalhada e "realista". Filmes como Face/Off souberam tirar proveito da falta total de limitações que o cinema contemporâneo tem 
para simular com precisão cirurgias "miraculosas", como a que faz John Travolta se transformar num sósia perfeito (ou meihor, em um "gêmeo cirúrgico") de Nicholas Cage. Portanto, o recurso à Medicina passou a ser um importante ingrediente do thriller policial hollywoodiano, que procurou revestir a fiç̧ão de maior verossimilhança, sem no entanto abrir mão dos imperativos simbólicos que fermentam a construção de sentido no âmbito deste gênero.

Em seu interessante ensaio sobre a história do corpo no cinema, Antoine de Baecque (BAECQUE, 1996) também salienta os vínculos do cinema hollywoodiano contemporâneo com a matriz frankensteiniana do cinema de horror, cuja principal característica é o tema da morte, ou melhor, da reaparição ou do "retorno à vida" do corpo após a morte, através de cadáveres e mortos-vivos. Segundo ele, o gênero fantástico (sobre cujo rótulo os teóricos franceses do cinema abrigam o filme de horror e o filme de ficção científica, entre outros gêneros e subgêneros) tem estado em evidência nos últimos anos. configurando um gênero em que o corpo é uma espécie de invólucro de algo imaterial ou material. algo que ele batizou de "o cinema do cadáver".

Creio que Face/Off não pode ser incluído nesta tradição ou nesta estética do cadáver, como a nomeia de Baecque, pois o filme de Woo mostra o triunfo, a precisão, a assepsia da intervenção cirúrgica. Referindose a Death Becomes Her (A morte the cai bem), de Robert Zemeckis, em que Meryl Streep e Goldie Hawn interpretam duas feiticeiras que se mantêm vivas depois da morte e cujo corpo (ou cadáver) passa a ser invulnerável à dor e às mais terríveis degradações físicas, e a filmes de Tim Burton e Sam Raimi, entre outros, de Bacque observa: "Les cicatrices, les coutures, les interstices, l'inachèvement, les traces de mutation. apparaissent comme les emblèmes de ces films, effets pervers et repoussants (fascinants aussi) de toute puissance du cinéma qui permet de coller les imagens unes aux autres." O que distingue Face/Off (que de resto não é um filme de horror) é exatamente a sua representação de uma Medicina que não apresenta as imperfeições e a perversidlade do moderno horror americano. Ele nos põe diante de uma Medicina infalível que superou completamente a fase das cicatrizes, das cirurgias que não se ocultam ou que salientam mais ainda o caráter mórbido do corpo humano. A tese de de Baecque porém é válida para a abordagem que faço de Face/Off, pois também no filme de Woo (e outros que adotam a mesma postura ideológica em face dos poderes da ciência) a característica fundamental apontada por de Baecque nos filmes do recente horror 
hollywoodiano se aplica: a ciência e a tecnologia (a Medicina, como sabemos, é uma área de aplicação por excelência das inovações científicas e tecnológicas) resolveu, no nosso tempo, o problema da morte e das limitações associadas ao corpo. Purgou aliás o corpo de um de seus maiores defeitos e imperfeições, que é a morte. Ao dominar plenamente o corpo, a Medicina não só o livrou da morte como o transformou em objeto de manipulação ilimitada, sendo capaz de, com o uso de tecnologias de última geração, produzir transformações (mutações) inimagináveis (e reversíveis) na aparência e na forma do corpo humano.

\section{O paradigma representacional}

O paradigma representacional é provavelmente o mais utilizado na abordagem da relação entre o cinema e a medicina. Ele consiste essencialmente no exame de personagens e situações médicas no cinema. Em geral, trata-se de uma abordagem realizada por médicos ou estudiosos muito familiarizados com as questões relativas à Medicina e à Ciência, que expressa uma perspectiva que tem nestas áreas o eixo central de análise (ainda que possa existir alguma familiaridade com a análise fílmica). Há diversos trabalhos que investigam esta relação de forma muito interessante. Vou citar apenas dois livros nesta linha, 84 para exemplificar a utilização do modelo representacional, isto é, análise de personagens e situações médicas no cinema.

Em seu livro Doctors in the Movies, o médico e escritor americano Peter Dans examina o instável relacionamento entre o cinema (hollywoodiano) e os médicos que ele costuma retratar, com resenhas de 74 filmes realizados entre 1931 e 1998 (DANS, 2000). O autor não se concentra apenas na análise dos filmes, abordando nos dez capítulos de seu livro temas interessantes como a visão das escolas de medicina por Hollywood, o número menor de mulheres médicas nos filmes, entre outros. Ele considera Not as a Stranger (Não Serás um Estranho, 1955, Stanley Kramer e Frank Kramer ) como um filme ideal para discutir a relação entre cinema e Medicina. O filme conta a história de um ambicioso mas pobre estudante de Medicina, interpretado por Robert Mitchum, que se casa com uma mulher mais velha (no filme, pelo menos) sem atrativos especiais (Olivia de Havilland), para que ela possa pagar as despesas de sua formação. $O$ elenco inclui ainda astros do porte de Frank Sinatra (colega e melhor amigo de Mitchum, que se torna um respeitável médico), Gloria Grahame (com 
quem Mitchum tem um caso), Lon Chaney Jr., Charles Bickford (mentor de Mitchum e que morre de ataque cardíaco em seus braços) e Broderick Crawford.

Outro livro que pode ser incluído nesta perspectiva é Psychiatry and the Cinema, escrito por dois irmãos, Glen O. Gabbard e Krin Gabbard, um psicanalista e outro crítico de cinema, cuja segunda edição foi lançada em 1999, 13 anos após a primeira. A primeira parte do livro é a mais interessante e é a mais diretamente ligada à Psiquiatria e à Medicina, pois os autores revisam com rigor o tratamento psiquiátrico e psicoterápico apresentado nos filmes, das fases iniciais da história do cinema até os dias atuais. Os imãos Gabbard procuram demonstrar como os filmes espelham ou não a realidade clínica.

Estes dois livros exemplificam bem a característica básica deste paradigma, que é promover uma espécie de abstração do filme como produto de invenção, resultado de uma elaboração estética. para interpretálo como um discurso "verossímil", portanto passivo de "crítical", sobre o objeto retratado. No caso, os médicos ou as instituições e agentes do campo psiquiátrico e psicanalítico. Para não enveredar na complexa discussão a respeito da consistência lógica deste paradigma. me contentarei apenas em mencioná-lo. Para o escopo desta abordagem. o paradigma seguinte é muito mais apropriado e muito mais pertinente.

\section{O paradigma biomédico}

Antes de qualquer coisa, gostaria de esclarecer que a Medicina em Face/Off deve ser entendida num contexto específico, especialmente aquela praticada no Laboratório de Operações Especiais do FBI. Lembro que a esposa de Sean Archer (John Travolta) é médica, mas há uma perfeita distinção entre o tipo de Medicina que ela pratica, ajustada às convenções tradicionais com que as instituições e os agentes médicos são retratados no cinema, e a que tem lugar no FBI. Aqui, se trata antes de uma Medicina para finalidades de segurança, de combate ao crime orgnizado. Os funcionários deste setor não sĩo propriamente médicos, mas "cientistas". Mais do que "cientistas", são "agentes" ou "oficiais" (para usar a terminologia do FBI real) a serviço do Governo americano.

Apesar destas ressalvas, creio que se possa ver a abordagem que o filme faz da Medicina nos termos do "modelo biomédico reducionista e dualista" que Susan McKay, em seu ensaio Beyond Biomedicine: Renegotiating the Sick Role for Postmodern Conditions $^{2}$, propõe para caracterizar o paradigma dominante na 
Medicina ocidental. Ele é caracterizado pela redução da saúde e da doença à química e à física e pela separação de corpos e mentes a partir da concepção dos corpos como máquinas. A concepção de MacKay é fortemente influenciada pelas idéias de Debora Lupton sobre as representações culturais dominantes da Medicina como uma instância de magia e um discurso autoritário e domesticador que propõe uma atitude passiva do homem em face de sua ação sobre seu corpo.

Uma outra perspectiva interessante nesta direção é a de David Morris, citado por McKay, segundo a qual a biomedicina é um discurso cultural, que pode ser interpretado como "uma narrativa modernista que vê a doença humana como uma disfunção de um mecanismo bioquímico, e não como uma experiência única de produção de sentido e incorporada no tecido social e cultural, como uma visão nova e dsafiadora deveria encará-la" ${ }^{3}$.

A cirurgia plástica é uma das tecnologias que permitiriam uma reengenharia do corpo humano que estaria em curso na era pósmoderna. A intervenção para fins estéticos ou reconstrutores sobre os corpos biológicos seria regida pelo princípio da eficiência, pela redefinição do papel da ciência e da Medicina não como instrumentos de superação das limitações humanas (sobretudo a Medicina 86 terapêutica e sua atuação contra a doença), mas no sentido de uma "expansão" das possibilidades do corpo pelo conhecimento da lógica genética e dos sistemas bioquímicos e biosífisicos que regem a vida humana. Para outra autora interessada no tema, Linda F. Hogle, os modernos procedimentos cirúrgicos, especialmente aqueles que envolvem os transplantes ou as substituições de partes do corpo, redefiniram o modo como as pessoas concebem os seus corpos físicos. ${ }^{4}$

\section{Parte 2 - O tema do duplo na cultura ocidental e no cinema}

Em linhas bem gerais, Face/Off tematiza o mal-estar da troca de identidade. $O$ fato de que no filme um corpo pode ser transformado em outro, pode ser convertido cirúrgica e biologicamente em "gêmeo" de outro, nos coloca diante da questão crucial do tema da identidade e também do tema do duplo, do monstro (Dr. Jeckyll versus Mr. Hyde) ou ainda do duplo macabro (o Doppelgänger, segundo os alemães) que habita dentro de nós e pode ser despertado em certas circunstâncias, enfim, do desdobramento maligno do homem que suscitou tantas obras importantes na cultura artística ocidental. 
A trama de Face/Off tem em seu núcleo temático um elemento que merece uma pequena digressão: a questão da dupla identidade. É verdade que a troca se dá essencialmente no plano físico, pois o agente do FBI e o megacriminoso têm ódio mortal um pelo outro e é com horror e rejeição máxima que assumem o corpo e a identidade um do outro. Apesar da troca, a consciência de si mesmos permanece e cles sabem quem eles são, ao contrário dos outros personagens, que se fiam apenas na "aparência física" (o corpo como exterioridade, como invólucro que oculta a verdadeira essência do indivíduo não é facilmente assimilável pelo senso comum) e custam a descobrir a verdadeira "identidade" dos corpos trocados. O paroxismo disto é a impressionante cena em que a fillha de Sean Archer atira no próprio pai, que não consegue ser convencida de que ele está preso dentro do corpo do terrivel Castor Troy. Para tratar desta questão do duplo, vou utilizar o conceito alemão de Doppelgänger, que apesar de sua abrangência é bastante pertinente para o exame de Face/Off.

Segundo o canadense Donald Totaro, o termo alemão Doppelgänger (literalmente, caminhante duplo, sombra, ou simplesmente, duplo) é um dos mais persistentes em todas as artes do século XX. Sua origem poderia ser encontrada na famosa metáfora da caverna de Platão, onde os espectadores aprisionados vêem sombras projetadas na parede, não conhecendo nada alćm desta existência reflexa, que eles assumem ser a "realidade" (TOTARO, 1999). O dogma da ilusão de realidade do cinema se baseia neste mesmo princípio, nesta reflexão, nesta possibilidade de duplicação da realidade.

Totaro informa que o termo foi usado inicialmente para definir um importante aspecto da arte alemã, começando com o Romantismo. ganhando maior definição no Expressionismo e se tornando um dos temas essenciais do Cinema Expressionista alemão (1919-1930). Alguns dos mais importantes filmes do movimento podem ser vinculados temática e formalmente ao tema do Doppelgänger. Em primeiro lugar, na construção de personagens: as duas Marias de Metropolis (1926, Fritz Lang), que expressam o "complexo prostituta/madonna" (TOTARO), os personagens divididos de Der Januskopf (A cabeça de Janus, 1920, Friedrich Murnau), uma adaptação do romance "O médico e o monstro" (1886), de Robert Louis Stevenson, a degeneração de caráter apresentada $\mathrm{em}$ de Der blate Engel (O Anjo azul, 1929, Josef von Stemberg) e em Der letzle Mann (A liltima gargalhada, 1924, Friedrich Murnau) e a imortalidade em Faust (Fausto, 1926, Friedrich Murnau). Totaro vê também o tema se manifestar 
na própria linguagem dos filmes, por exemplo, a iluminação chiaroscuro e o uso freqüente de reflexos no espelho. $O$ conceito pode ser ampliado a ponto de ser associado ao dualismo que marca o eixo temático de filmes de vários gêneros, especialmente a ficção científica (Invasion of the Body Snatchers, Planet of the Apes, Seconds, Frankenstein, Solaris), que articulam pares antitéticos mente/corpo, ciência/religião, natureza/cultura etc.

Acho que algum cuidado deve ser tomado na utilização deste conceito, pois ele pode servir como uma forma de explicar segundo um único ponto de vista estruturas narrativas muito diferentes umas das outras. Totaro chega a ponto de estender o conceito para a comédia, citando os papéis duplos interpretados por Chaplin (por exemplo, em The Great Dictator, em que faz o barbeiro e o ditador) ou Monsieur Verdoux, onde leva uma vida dupla de assassino no estilo Barba Azul e marido zeloso.

Totaro tem toda razão: nenhum gênero porém explorou mais o tema que o filme de horror. Uma série de termos duplos pode ajudar a resumir diversas modalidades ou formas do gênero horror: vivos/mortos (vampiros, zumbis, o monstro de Frankenstein), bem/mal, anjos/ demônios, homem/monstro (vampiro, lobisomem, médicos ou cientistas loucos como o Dr. Jekyll e Mr. Hyde, o homem invisível). Também podem ser incluídos aqui os casos de personalidade dividida (Psicose, Irmãs diabólicas, o já citado Dr. Jekyll e Mr. Hyde, The Nutty Professor, entre outros).

Em sua análise de como os gêneros cinematográficos constroem a sua representação do duplo, Totaro percebeu bem que a forma como cinema seleciona e utiliza os atores é um dado importante nesta análise do duplo no cinema. Segundo ele, a forma mais comum é a utilização de um mesmo ator para dois papéis diferentes, em filmes como o já citado $O$ Grande ditador, Vertigo ${ }^{5}$ e centenas de outros exemplos. É comum, por exemplo, que um ator interprete pai e filho no mesmo filme, com a ajuda de uma boa maquiagem; por exemplo, La strategia del ragno, de Bernardo Bertolucci. Há casos, porém, que revelam um uso mais audacioso dos efeitos de duplicação de personagem, isto é, quando dois atores diferentes vivem um mesmo personagem. O exemplo óbvio é Cet obscur object du desire (Este obscuro objeto do desejo, 1978, Luiz Buñuel,) onde a criada de Fernando Rey é interpretada por duas atrizes diferentes, de forma intercalada (Carole Bouquet e Angela Molina ${ }^{6}$ ). Esta é, segundo o próprio Totaro, a matriz de Face/Off, "onde dois personagens trocam os rostos e devem 'atuar' e se comportar como seu antagonista". 
Na categoria de duplos, poderíamos incluir também os filmes sobre gêmeos, que existem desde os primórdios do cincma narrativo. c os filmes sobre clones, em evidência nos últimos ános em virtude dos avanços da ciência no terreno da clonagem do DNA. Neste último caso, há que se distinguir entre os filmes que tratam da geração de seres individuais através da manipulação do DNA daqueles que tratam da cópia genética de seres humanos (ou não-humanos, de que não tratarei aqui). Assim. mencionaria como exemplos, na categoria de gêmeos. o clássico A Stolen Life (Uma vida roubada, 1946, Curtis Bernhardt) com Bette Davis e Glenn Ford. onde Davis interpreta irmãs gêmas, e o perturbador Dead Ringers (Gêmeos, Mórbicla Semelhança, 1988, David Cronenberg). onde Jeremy Irons interpreta dois estranhos médicos gêmeos; entre tantos filmes contemporâneos que abordam o tema da clonagem. citaria Multiplicity. (Eu, Minha Mullher e Minhas Cópicas, 1998. Harold Ramis). com Michael Keaton e Andy MacDowell. onde Keaton é um homem que resolve se clonar em quatro para dar conta de suas muitas atividades. e O Sevto Dia (The Sixth Day, Roger Spottiswoode, 2000), um retrato sombrio da ciência que começa no título bíblico que fala do dia em que Deus criou o homem, onde Arnold Schwarzenegger é um piloto de helicópteros que volta para casa após um acidente e descobre que foi substituído por um clone.

O cinema contemporâneo apresenta tratamento mais radical e

severo do tema, como por exemplo, em Chungking express (Chunghing Samlam (título cantonês) ou Zhongring Senlin (título mandarim), 1994, Wong-Kar Wai), onde um grupo de personagens mostrado no começo da história é substituido inexplicavelmente por outro, ou de forma mais radical ainda, com as mutações constantes de personagens e atores em Lost Highway' (A Estrada Perdida, 1996. David Lynch). Estes exemplos, entre centenas que poderiam ser apresentados aqui, mostram a atualidade c. sobretudo. a inexauribilidade do tema do duplo no cinema.

\section{Parte 3 - Face/Off e o tema da identidade}

\section{O diretor}

Nascido Wu Yu Sen em 1" de maio de 1946 na província cantonesa de Guangzhou, na China, de pais cristãos e com situação financeira muito modesta, John Woo mudou-se aos três anos com a família para Hong Kong para escapar à Revolução Comunista. Influenciado pela mãe, que o levava ao cinema para ver os filmes ocidentais, Woo decidiu desde cedo 
que se tornaria um diretor de cinema. Após concluir seus estudos básicos, juntou-se a um grupo de amigos para promover sessões de filmes de arte europeus e para discutir os filmes assistidos. Em 1960, Woo obteve a sua primeira oportunidade na carreira como supervisor de roteiro nos Estúdios Cathay, em Hong Kong. Dois anos depois, tornou-se assistente de direção no Shaw Studios, onde teve como mentor Chang Cheh, que Ihe inspirou a arte de filmar cenas de ação e a importância da montagem para o gênero que então despontava em Hong Kong. Sua estréia como diretor ocorreu em 1973 com "The young dragons", um típico exemplar do gênero kungfu que todavia apresentava já dois elementos que mais tarde caracterizariam o estilo John Woo: o trabalho dinâmico e fluido da câmera e as sequiências de ação elaboradamente coreografadas (a cargo do futuro superastro do gênero Jackie Chan). Woo fez em seguida alguns outros filmes de artes marciais, mas acabou se firmando como um diretor de comédias, a partir do sucesso de "The Pilferer's Progress", estrelada pelo popular comediante de Hong Kong Ricky Hui. Em meados dos anos 1980, Woo resolveu dar uma guinada em sua carreira, que não ia muito bem, e realizou Alvo duplo (Yinghung bunsik, 1986), que estabeleceu um novo paradigma para o cinema de Hong Kong, então marcado pelos filmes de artes marciais e as comédias. Os filmes com tiroteios não agradavam ao público chinês, que os considerava tediosos em comparação com os movimentos fantásticos do kung-fu e os elegantes combates de espada dos épicos Wu Shu. Woo integrou as acrobacias e a graça dos filmes tradicionais de artes marciais com uma série de recursos visuais próprios do cinema, como travellings arrojados, filmagem em câmera lenta para criar sequuências de ação surrealistas e uma montagem desconcertante. Estudiosos do cinema de Woo consideram que ele criou uma curiosa e irresistível estetização da violência. Uma outra característica de seus filmes é a "intimidade" física que ele estabelece entre protagonistas e antagonistas, que buscam se confrontar face a face. Temas como a lealdade e a honra são recorrentes em seus filmes (e de resto, fazem parte de uma certa ética chinesa cara ao cinema de Hong Kong), embora seus heróis nem sempre tenham contole sobre as consequiências de suas ações e não estejam livres de contradições morais. Algumas marcas de seu estilo também podem ser destacadas: Woo gosta de usar espelhos em suas seqüências de ação. Há duas particularmente eletrizantes em Face/Of: a primeira é quando Sean Archer (John Travolta) acorda após a cirurgia que o transformou em Castor Troy (Nicholas Cage) e é colocado diante do espelho, tendo um acesso de fúria que o leva a espatifá-lo; a segunda, também impressionante, é a que John 
Travolta e Nicolas Cage, de identidade trocada. se defrontam diante de um espelho dos dois lados da parede de uma sala e atiram contra o espelho, mirando na imagem de seu "duplo" (que é refletida). Outra marca registrada de Woo são as armas duplas usadas pelos seus personagens.

O sucesso internacional de Alro duplo marcou uma nova era do cinema de Hong Kong, que os americanos batizaram de Heroic Bloodshed (algo como "matança heróica"). Woo fez em seguida diversos filmes que consolidaram seu estilo e sua reputação no gênero de ação, como No coração do perigo (Ying xiong wei lei. 1986). Alvo duplo II (Yingriong Bense II. 1987), The Killer - O Matador (Diexue Shuang Xiong, 1989), Bala na cabeça (Diexue Jietou. 1990), Rajada de fogo (Zongsheng sihai. 1991) e finalmente Fenvura máxima (Lashou Shentan. 1992), seu último filme $\mathrm{cm}$ Hong Kong antes de seu eslabelecimento em Hollywood. Com O alio (Ilard Target, 1993), Woo iniciou uma carreira no cinema americano marcada por grandes orçamentos, astros cada vez mais grandiosos (dirigiu Tom Cruise em Missão Impossírel 2. 2000) c um acabamento técnico impecável. Antes de Face/Off, Woo dirigiu outro grande sucesso. A última ameaça (Broken Arrow, 1996), onde dirigiu John Travolta pela primeira vez. Fez ainda Once a Thief (1996). remake de seu filme chinês de 1991. Após Face/Off, ele realizou cm 1998 Blackjack. estrelado por Dolph Lundgren. Woo dirigiu ainda King's ransom e Windtalkers, ambos de 2001.

\section{A produção de Face/Off}

Face/Off é o terceiro filme americano de John Woo e seu maior sucesso de bilhetcria até então, arrecadando, só nos Estados Unidos, mais de 112 milhões de dólares. No roteiro original. tratava-se de um filme no gênero "science fiction". cuja história se passava num futuro distante. John Woo sugeriu que a trama fosse adaptada para os dias atuais, a fim de inserir novos elementos psicológicos e dramáticos aos personagens.

A primeira versão do roteiro de Face/Off foi escrita em 1990) pelos roteiristas Michael Colleary e Mike Werb com Arnold Schwarzenegger ou Sylvester Satollone em mente. ${ }^{7}$ Werb e Colleary se inspiraram em White lleat, (Fúria Sanguinairia, Raoul Walsh, 1949), com James Cagney e Virginia Mayo, por sua vez inspirado na vida real do gangster de múltipla personalidade Arthur "Doc" e sua mãe Ma Barker: (A idéia de um policial que entra disfarçado numa 
prisão, como vemos em Face/Off, é extraída do filme de Walsh.) Em 1991, o roteiro foi oferecido a Joel Silver para ser produzido pela Warner Bros., mas a companhia não deu continuidade ao projeto. Em 1992, Werb e Colleary venderam os direitos à Paramount, com o compromisso de serem co-produtores do filme. Michael Douglas, ator e produtor de grande prestígio, associou-se ao projeto e seu tornou o principal produtor, ao lado de Steven E. Reuther e Johathan D. Krane.

Ao todo, a produção de Face/Off se estendeu por 7 anos, passou por 2 estúdios e teve 14 produtores, com 3 diretores trabalhando na adaptação (sendo que Woo foi o definitivo). Foram escritas mais de 30 versões do roteiro, sem mencionar as cenas adicionais escritas pelos roteiristas na pós-produção. Lançado em 27 de junho de 1997, Facel Off foi o grande hit do verão daquele ano, tendo recebido críticas bastante favoráveis em todo o mundo. O reconhecimento "artístico" porém foi limitado: o filme recebeu apenas uma indicação para o Oscar, na categoria de Melhor Edição de Efeitos Sonoros (Per Halberg e Mark P. Stoeckinger).

Face/Off apresenta muitas cenas em slow-motion e ação coreografada, edição ágil, violência gráfica com planos de impacto físico e bélico hiperdetalhados (Woo é famoso pelos planos filmados a partir

92 do ponto de vista de balas, projéteis ou mísseis detonados, da origem ao alvo), tudo recheado com poderosos jatos de hokum e embalado por uma trilha sonora (música e ruídos) de avassalador impacto emocional.

\section{Sinopse}

Como todo bom thriller hollywoodiano, Face/Off possui um enredo bastante rebuscado do ponto de vista narrativo, um verdadeiro labirinto de tramas e subtramas, estruturado segundo a lógica sherlockiana que informa toda uma longa tradição do gênero policial em sua feição "clássica". Portanto, não se espere aqui uma descrição do enredo do filme em poucas linhas.

Ambientado em Los Angeles, Face/Off retrata o duelo implacável entre um obstinado agente do FBI, Sean Archer (John Travolta) e seu arquiinimigo, a quintescência do mal e a encarnação de todos os estereótipos possíveis de um gênio do crime, ocínico, ultraviolento, psicótico eimprevisível Castor Troy (Nicholas Cage). Archer está obcecado em prender Troy, 
que anos atrás havia assassinado seu filho Michael (Myles Jeffrey) num parque de diversões, na tentativa de alvejar o agente. Esta obsessão desequilibra o casamento de Archer com a médica Eve (Joan Allen) e seu relacionamento com a filha adolescente problemática Jamie (Dominique Swain). Após uma perseguição que culmina em sangrento duelo num hangar de aeroporto, Archer consegue capturar Troy e seu trauma pessoal parece resolver-se. Porém, Archer descobre que Troy havia colocado em local ignorado uma bomba relógio com alto poder destrutivo e substâncias químicas letais, capaz de riscar do mapa a cidade de Los Angeles. Devido aos ferimentos sofridos durante o duelo com Archer, Troy está em coma no "centro médico" do Laboratório do FBI e não pode ser interrogado. A única outra pessoa que conhece a localização da bomba é o irmão mais novo de Troy, Pollux (Alessandro Nivola), preso numa penitenciária de segurança máxima e de quem a polícia e o FBI nada conseguem. O FBI propõe a Archer um plano fabuloso, inacreditável: em seus sofisticados e ultra-modernos laboratórios científicos, eles desenvolveram técnicas de cirurgia experimental que possibilitariam transplantar temporariamente o rosto de Troy na cabeça de Archer; ou seja. poderiam fazer uma troca cirúrgica de identidade entre Troy e Archer. Com isto. assumindo a identidade de Troy, Archer poderia se aproximar de Pollux e obter dele a informação sobre a localização da bomba a tcmpo de desarmá-la. Archer reluta em aceitar a idéia, mas diante da lembrança do filho assassinado por Troy, resolve submeter-se à operação, que é um sucesso. Enquanto Archer, transformado em Troy, entra na prisão c se aproxima de Pollux. Troy recobra a consciência e rende os médicos que o operaram, forçandoos a transplantar nele o rosto de Archer. O gênio do crime ressurge como o agente do FBI, com a lei do seu lado, passá a perseguir o falso Troy, que foge da prisão e tenta retomar o scu lugar, mesmo com o corpo trocado. A partir daí, o filme se toma um veículo para as cenas de ação ritmadas por coreografia de balé que o mestre Woo sapeca sem piedade. num crescente dramático que culmina num mortal combate dentro de um barco em alta velocidade. No final, Archer consegue retomar o seu corpo e com ele, a sua identidade. Bem, esta é em suma a história de Face/Off.

\section{A transformação}

A seqüência da transformação cirúrgica é, pelo menos dentro da perspectiva deste trabalho, a mais impressionante do filme e pode ser analisada como resultante da combinação de duas marcas estilísticas 
de Woo: uma decupagem bastante fragmentária associada a uma montagem rigorosa e um clima de sonho ou magia propiciado por uma música envolvente, de acento litúrgico. É uma sequiência de pouco mais de 6 minutos de duração (cronometrei 6 min. e 14 s.), relativamente longa para um thriller policial cujos ingredientes básicos são ação vertiginosa e diálogos de forte impacto e humor desconcertante. Mas este cuidado em mostrar lentamente o processo de transferência da identidade física de Sean Archer e Castor Troy tem sua lógica dentro da retórica narrativa de Woo. É o momento em que a "consultoria técnica especializada", a que a chamada Pesquisa de Arte do cinema americano sempre recorre na busca de correspondência entre o que aparece na tela e a realidade concreta, pode mostrar o seu empenho e a sua competência. A produção recorreu a dois Medical Consultants, Randy Ito e Terry Miller.

Entretanto, devo ressaltar que não há muito rigor nisto, pois sabemos desde o início que Face/Off é um thriller, que não se baseia em convenções de verossimilhança. Há o uso de elementos mais ou menos ajustados a um referencial de realidade, mas não há procupação com o respeito estrito à realidade.

A sequiência começa com o diálogo entre o agente Tito Biodi 94 (Robert Wisdom) e Sean Archer, quando este já está em seu bastante informal estágio "pré-operatório" no Laboratório de Pesquisas Médicas do FBI, aguardando a cirurgia transformadora. $\mathrm{O}$ agente quer dissuadir Archer de fazer a cirurgia, cujo sucesso ele coloca em suspeita (ao contrário da agente Miller ( $\mathrm{CH}$ Pounder), que em sequiência anterior garantiu a Archer a total segurança e reversibilidade do procedimento cirúrgico a que se submeteria). A falta de conviç̧ão de Archer também é parecida, pois ele responde a Tito com certo enfado:

Quem sabe se esse médico fizer metade do que prometeu. Talvez dê certo. Sei lá... Viro Castor e resolvo tudo.

A resposta de Tito é sintomática de seu temor não quanto ao sucesso da cirurgia, mas nas conseqüências desta experiência para a "cabeça" de Archer:

Isto é o que me dá medo.

Vemos que Archer e o agente não estão nem um pouco seguros quanto ao sucesso da cirurgia. A Medicina miraculosa do FBI não os impressiona. Aparece então o médico, Dr. Malcolm Walsh, não sem propósito todo vestido de preto. Archer poderia ter feito vários comentários bem contundentes e engraçados (Colleary e Werb conseguiram se conter) 
sobre a cirurgia, mas o que ele faz é um pedido de ordem muito pessoal. Ele mostra ao médico uma cicatriz no abdômem (do tiro que levou de Castor Troy no começo do filme) e pede para ele colocá-la de volta quando tudo terminar. "É um lembrete", esclarece ele.

A cirurgia é realizada no centro cirúrgico, em outro andar do prédio. A sequiência começa com um corte scco - na sequiência anterior. Archer avisa a mulher que decidiu fazer a cirurgia para cumprir a perigosa missão e beija a filha que está dormindo no quarto. Não há diálogos durante toda a cirurgia - música e ruídos (bips e outros sons cmitidos pelos equipamentos e instrumentos cirúrgicos que ressaltam a precisão e a sofisticação tecnológica da operação) marcam a sequiência inteira.

O Dr. Walsh usa uma caneta (não sei se especial ou uma simples esferográfica) para contomar o rosto de Castor, marcando o percurso da incisão que será feita para removê-lo por inteiro. Usa para isto um bisturi a laser, que não emite uma luz azul típica mas uma forte luz incandescente. que "queima" a linha de contorno do rosto de Castor. Após a incisão. é utilizado um molde transparente do rosto de Castor para remover com precisão e suavidade a pele de scu rosto. que é colocada $\mathrm{cm}$ meio líquido antisséptico. O mesmo é feito com o rosto de Archer.

Evidentemente, a cirurgia não é mostrada em todos os scus detalhes, quero dizer, mesmo em se tratando de fato normal a condensação de uma cirurgia com duração de várias horas dentro do "tempo cinematográfico", determinados estágios do processo são suprimidos ou não foram filmados por opção de Woo ou dos "consultores especializados", ou ainda, por contingências do setor de maquiagem e efeitos especiais. Por exemplo. o rosto "desencarnado" de Castor ou Archer nunca é mostrado, pois a ética de Woo não permite monstruosidades deste tipo.

Após o implante de pêlos no corpo e o retoque dos cabelos. Archer recebe a máscara facial interiçal de Pollux, que é "soldada" a laser em sua cabeça. A soldagem é perfeita: nenhuma cirurgia, nenhuma marca que denuncic uma cirurgia. É portanto atingido o grande desiderato de toda a cirurgia, especialmente a plástica, que é a ausência total de cicatrizes.

Após uma elipse bem razoável (Woo preferiu não mostrar a lipoaspiração para remover as gorduras de Archer), vemos o agente já transformado em Castor Troy, com bandagens cobrindo-lhe o rosto. deixando expostos apenas os olhos. As bandagens são removidas e Archer é posto diante de um espelho (objeto que não pode faltar num 
filme de Woo) para ver sua nova aparência. Diante da "imagem" de seu arquiinimigo, num acesso de fúria ele espatifa o espelho e xinga a todos os que estão à sua volta. Quando o agente negro o chama pelo nome, Sean, ele se acalma.

Um microchip é implantado na garganta de Archer para que ele fique com a voz de Castor. Na verdade, é a voz de Nicholas Cage que se houve o tempo todo, pois Woo não deu muita importância a isto (talvez para ele fosse pouco convincente que Cage e Travolta se dublassem mutuamente, em benefício de uma continuidade lógica estrita). A última imagem desta sequiência é o corpo sem rosto de Castor coberto de bandagens.

Gostaria de fazer algumas observações talvez um pouco vagas sobre os procedimentos adotados pelos cientistas do FBI, não para encontrar falhas de continuidade ou na representação verossímil de um ambiente cirúrgico, mas para ressaltar algumas características que dão a esta cena um efeito perturbador. Em primeiro lugar, Woo procurou não mostrar o ambiente cirúrgico em detalhes. Os assistentes - médicos e enfermeiras - estão sempre ao fundo, enquadrados em planos cujo foco não lhes alcança. Não vemos os seus rostos. Outra coisa: para a complexidade da cirurgia realizada, até que são poucos os assistentes, cinco ou seis no máximo. Um detalhe me chamou a atenção: o molde transparente personalidado usado para "arrancar" o rosto de Archer é tem código - Archer 44A597-A.

Esta falta de um maior detalhamento em relação ao ambiente cirúrgico pode ser uma mera opção "estética" de Woo e pode ser justificada em função de critérios de produção ou funcionalidade narrativa, mas gostaria de oferecer uma hipótese mais sugestiva para isto. Creio que ela se deve ao fato de que, apesar de toda a precisão na construção cenográfica de um centro cirúrgico, na composição "técnica" da mesa de operações, na adequação com os elementos encontráveis num ambiente médico real, esta cirurgia não é totalmente plausível. Não apenas porque todo mundo sabe ou intui que a cirurgia é (ainda que parcialmente) inverossímil, e que a Medicina (mesmo a praticada em instituições mais "livres" de restrições éticas da comunidade científica e médica como o FBI) não tem e talvez nunca tenha condições de realizar semelhante transposição de rostos e outros elementos do corpo de um indivíduo para outro. $\mathrm{O}$ tratamento que Woo dá a esta transformação é o de um procedimento mágico. Para ele, a Medicina "real" não interessa senão como veículo para explorar uma instância mágica que não tem qualquer limite ou restrição, que pode fazer 
qualquer coisa, por mais absurda que pareça, se concretizar diante dos olhos dos espectadores. O mais interessante nesta forma de "apropriação" da tecnologia médica é que ela é feita dentro de um pretenso respeito e conformação ao estágio presente da ciência médica. Cabe também observar que as modernas tecnologias de efeitos especiais permitem que Face/Off supere algumas "limitações" da cirurgia plástica: os procedimentos essenciais são respeitados e seguidos à risca, mas são introduzidos alguns elementos que permitem atingir mais plausivelmente os objetivos pretendidos. Por exemplo, o molde transparente do crâneo frontal de Archer, usado para "puxar" seu rosto suavemente, parece ser algo tecnicamente implausível, pois os vasos sanguíneos, os tecidos, as ramificações nervosas que ligam as varias camadas da pele do rosto de Archer ou Castor não são seccionadas para justificar uma remoção de forma tão suave. $O$ rosto é arrancado muito facilmente por um processo que se vê nitidamente que é mecanico (não há nenhuma aplicacão de laser senão nos contornos exteriores do rosto).

Concordo com Barbara Lupton que estamos diante de mais um caso de apologia da "magia médica" (LUPTON, 1994, p. 53). Mas não se trata a meu ver de mistificação e idealização da Medicina. $O$ discurso do filme em relação à Medicina, como já observei, me parece mais negativo que positivo. Antes do que celebrar as possibilidades ilimitadas e miraculosas oferecidas por ela, o filme expõe um temor pelas conseqüências perversas de uma manipulação extrema do corpo e da identidade física do homem.

Há várias seqüências politicamente incorretas nesta sequiência chave. Em uma delas, a cientista do FBI Hollis Miller ( $\mathrm{CCH}$ Pounder) e Sean Archer vão ao Centro Médico do Laboratório de Operações Especiais do FBI, onde Castor Troy está internado, em estado de coma, monitorado por aparelhos. Sean se enfurece quando descobre que Castor ainda estava vivo. Mas a agente Miller o tranquiiliza. "Calma, ele é como um vegetal". E para assegurar o caráter inofensivo do criminoso, ela apaga uma ponta de cigarro (que acendeu no início da cena, mas não se vê ela fumando ou tragando) sobre o peito de Castor.

Miller propõe neste momento que a única uma forma de evitar a explosão da bomba que Castor colocou em algum ponto de Los Angeles: Archer poderia ser transformado em Castor Troy. Aparece então o Dr. Malcolm Walsh (Colm Feore), do Laboratório de Operações Especiais, para explicar como isto poderia ser feito. Diz que seu laboratório é especializado em alterações físicas, mudanças de voz, 
estas coisas já bem corriqueiras na Medicina que os roteiristas imaginaram. Para exemplificar isto, O Dr. Walsh mostra o processo de reconstrução da orelha de um agente ferido no tiroteio com Castror Troy. O Dr. Walsh diz que não seria um transplante permanente, mas temporário. Segundo ele, com os novos antinflamatórios, a cicatrização seria rápida. Usariam laser no cabelo, fariam microimplantes de pelo, e uma plastica abdominal. Dr. Walsh é taxativo em sua crença na ciência e na tecnologia:

- Essa é a parte fácil, é ciência pura.

Ele mostra então o molde do crânio de Sean - obra-prima da morfogenética, segundo ele. $\mathrm{Na}$ verdade, ele deveria ter dito Biotecnologia e não Morfogenética, pois esta é o estudo do desenvolvimento dos mecanismos celulares, genéticos e epigenéticos dos organismos biológicos.

Para ele, tudo seria muito simples:

É só ligar os músculos, canais lacrimais e nervos.

\section{O tema da identidade e a Cirurgia Plástica no cinema}

Um dos temas mais importantes - na verdade, o tema mais

98 importante - de Face/Off é o da identidade. Sob este aspecto, o filme poderia ser comparado a uma extensa lista de outros filmes baseados no mesmo princípio. É interessante detalhar estas analogias (ou possíveis analogias) para construir uma espécie de catálogo de filmes que tematizaram a questão da troca de identidade, sob várias facetas. Creio que Face/Off é um caso singular, pois a transformação física de um homem em outro (com reversão posterior garantida) que o filme apresenta se dá na esfera científica e médica, embora, como veremos, a Medicina seja apropriada pela narrativa de Face/Off de uma forma bem peculiar à fabulação hollywoodiana, ou seja, sem muito rigor no aspecto da objetividade científica. ${ }^{8}$

Em primeiro lugar, eu sugeriria uma tentativa de classificação destes filmes em quatro ou cinco grupos:

1. Filmes sobre o duplo, a duplicação do corpo

Doppelgänger - o duplo maligno: $O$ Golem

Sósias - O Grande Ditador

Gêmeos - Dead Ringers - Gêmeos - Mórbida Semelhança, 1988)

2. Filmes sobre mestres dos disfarces e caracterizações - Missão Impossível de Brian de Palma 
Mutações biotecnológicas: o caso mais fantástico é $O$ Exterminador do Futuro II, de James Cameron

Clones e clonagem no cinema - Multiplicty - Eu, Minha Mulher e Minhas Cópias, de Harold Ramis, 1996 -

Duplicação ou transformação pela Magia: Excalibur; John Boorman, 1981-O Mago Merlin transforma Arthur no Rei para possuir Guinevere

3. Filmes sobre a troca de personalidade ou de consciência Trocas corporais (body change): Vice Versa, etc.

4. Filmes sobre possessão espiritual, maligna ou benigna

Corpos vivos invadidos - Imvasores de Corpos Invasores (The Invasion of the Body Snatchers) 1978 - Body Snatchers. Philip Kaufman 1983.

Reencarnação - cadáveres possuídos por espíritos

Transferência de almas - anjos, entidades do mal; caso recente: Enigma do Espaço - The Astronaut 's Wife -. Rand Ravich 1999

5. Cirurgias transformadoras

His Kind Of Woman

Les Yeux Sams Visage

Seconds

Uma outra distinção importante em relação a Faceloff é que o filme apresenta uma visão estrita do ato cirúrgico, circunscrita a um registro realista (relativo, é verdade). Apesar dos naturais "exageros" ou "inverossimilhanças" da unidade cirúrgica do centro de pesquisas do FBI, dentro de uma análise mais rigorosa que poderia ser feita, é destacar que o filme aborda a cirurgia plástica de um modo também realista. Há sem dúvida um "milagre", que é a transformação física de um homem em outro, mas o roteiro e a direção evitaram soluçôes relacionadas a próteses ou artefatos biônicos. É estritamente uma intervenção segundo as técnicas da cirurgia plástica, que no filme se encontra naturalmente num estágio mais avançado que a cirurgia plástica real.

Em paralelo, poderíamos evocar outras situações semelhantes no cinema, isto é, personagens que se submeteram a cirurgias plásticas para mudarem a aparência do rosto ou se transformarem em outros personagens. Parece-me que o exemplo que guardaria maior afinidade com Face/Off seria His kind of woman, filme noir dirigido em 1951 por John Farrow, estrelado por Robert Mitchum, Vincent Price. Jane Russell e Raymond Burr, entre outros. Como no filme de Woo, a cirurgia plástica é elemento 
fundamental na trama de "troca de identidade" criada pelos roteiristas Frank Fenton e Jack Leonard. Nick Ferrero (Burr), um gangster deportado para a Itália, pretende retornar aos Estados Unidos para retomar suas operações tomando o rosto e a identidade de um cidadão americano. Um jogador profissional, Dan Miller (Mitchum), aceita a proposta de viajar para um luxuoso resort mexicano em Morro's Lodge e "vender". a sua identidade para Ferrero, em troca de 50 mil dólares. Mas ele percebe que a troca será definitiva e que será assassinado e não escondido, como o prometido, tendo que lutar para salvar a pele e a própria identidade.

Vale lembrar que durante a década de 1930 , o Motion Picture Production Code, mais conhecido como Código Hays, sugeria que se evitassem as imagens cirúrgicas nos filmes americanos. "Surgical operations" eram incluídas na categoria de "Repellent Subjects" pelo código, ao lado de enforcamentos ou eletrocutações como punições legais de crimes, brutalidade, marcações a ferro incandescente em animais ou seres humanos, crueldade aparente com crianças e animais, o comércio de mulheres ou uma mulher vendendo a sua castidade, entre outros: ${ }^{10}$

\section{XII. Repellent Subjects}

\section{Código Hays}

The following subjects must be treated within the careful limits of good taste:

1. Actual hangings or electrocutions as legal punishments for crime.

2. Third degree methods.

3. Brutality and possible gruesomeness.

4. Branding of people or animals.

5. Apparent cruelty to children or animals.

6. The sale of women, or a woman selling her virtue.

7. Surgical operations.

Nesta busca de antecedentes para Face/Off, podemos perceber uma interessante similaridade também com Les yeux sans visage, filme de horror poético dirigido pelo francês Georges Franju em 1959 (exibido em junho de 2001 na mostra O Homem e a Máquina, dentro do evento Carlton Arts, realizado em São Paulo). Pierre Brasseur interpreta um brilhante cirurgião plástico (Prof. Genessier) determinado a reconstruir o rosto de sua filha Christianne (Edith Scob), que foi desfiguradó em um acidente de automóvel provocado pelo próprio cirurgião (ela usa uma máscara para ocultar a 
deformação). Com a ajuda de sua assistente Louise (Alida Valli), ele rapta jovens bonitas e remove seus rostos para transplantá-los em sua filha. As tentativas, que custam a vida de várias moças, não obtêm sucesso. A semellhança com Face/Off está na técnica de "extração" cirúrgica do rosto (isto é. da mascara facial)e a sua implantação em outra cabç̧a. Franju expõe, antecipando de certa forma Gêmeos, de David Cronenberg, o lado sombrio da Medicina e suas funestas tentativas de manipular e transformar os corpos humanos.

Seconds" (Segundo Rosto. John Frankenheimer, 1966) apresenta uma sequiencia cirúrgica de forte impacto. quando o personagem de John Randolph é submetido a uma cirurgia de rejuvenescimento que o transformará num novo homem, com nova identidade (Rock Hudson). Cirurgias como solução mágica para o envelhecimento também aparecem em vários outros filmes. Em alguns casos, são apenas mencionadas e não mostrados (não vemos as transformações cirúrgicas, mas sim os personagens depois de submetidos a estas cirurgias transformadoras.)

\section{Uma análise de Face/Off}

Vimos que o personagem de John Travolta inicialmente é categórico em recusar a idéia de submeter-se à cirurgia "experimental" (sem dúvida, ele seria cobaia de uma técnica cirúrgica que nunca havia sido posta em prática, mas este tipo de risco é o menor diante da vida nem um pouco sossegada que levava o agente do FBI).

Embora a cirurgia realizada cm Sean Archer (e mesmo a feita em Castor) seja um sucesso absoluto, nĩo deixa de ser significativo este diálogo entre o cientista do FBI, Tito. e Archer. em que o primeiro tem dúvida não quanto ao êxito da cirurgia, mas das consequiencias que traria para a vida de Archer. É quase uma advertencia sobre os riscos de uma manipulação radical na integridade do corpo humano, nos efeitos psíquicos da transmutação, principalmente aquela de extraordinário risco que o FBI pretende fazer - transformar um homem do "bem", um condecorado oficial do FBI no pior criminoso da América, um terrorista frio c quase "desumano" como Castor Troy.

Sean Archer tem um terrível receio desta "descida aos infernos" que é assumir, ainda que provisoriamente. a identidade e o corpo de Castor. Ele teme pelo que possa acontecer com ele e sua família se algo der errado neste mirabolante plano.

Sob este aspecto, no roteiro de Fice/Off repercute a mesma inquielação característica da ficção científica (observe-se que o filme foi concebido como 
um filme de ficção científica e se passaria num futuro distante, mas Woo sugeriu trazê-lo para a época atual pensando que os avanços da tecnologia médica permitiram as situações exibidas no filme) com os efeitos perversos da tecnologia, da intervenção do homem no âmago secreto da natureza. Este medo dos efeitos da ciência tem nexos com o mito de Prometeu, que roubou o fogo dos deuses para entregá-los aos homens e atraiu a ira e a maldição decorrentes da violação de uminterdito.

Gostaria agora de numerar algumas conclusões (ou reflexões) suscitadas pela relação estabelecida pelo filme com a Medicina:

1. A medicina do FBI não é a Medicina oficial, é uma Medicina futurista, dedicada a prover elementos e recursos para o combate ao crime. Neste sentido, nãoé a legítima Medicina que está em cena, mas um departamento "científico" que tem a mesma natureza que aqueles de outras organizações de segurança e polícia, fictícias ou reais, retratadas no cinema, destinadas a fornecer próteses para camuflar os agentes (máscaras, disfarces). Missão Impossivel é um exemplo.

2. Em relação à questão da cirurgia, observe-se que a moderna Cirurgia Plástica éalgo ainda relativamente recente, tendo se desenvolvido intensamente durante a Segunda Guerra Mundial devido à necessidade de os cirurgiões das unidades médicas do fronts de guerra de reconstuir os teríveis ferimentos faciais dos soldados. Desta finalidade terapêutica básica, a Cirurgia Plástica se dividiu em Reconstrutora e Cosmética, onde, apesar do esforço da classe médica em diminuir as diferenças de cada uma delas, houve uma apropriação simbólica e cultural (ideológica) da Cirurgia Plástica com finalidades estéticas pela sociedade americana a partir dos anos $1950 . .^{12}$

3. A questão da credibilidade - A representação da Medicina pelo cinema poderia ser mais "verossímil" ou mais "plausível" com uma rigorosa supervisão médica especializada estrita? Estaé uma questão que se baseia na velha premissa da correspondência estritia entre o cinema e a ralidade, de que Hollywood se esquiva o mais que pode. Evidentemente, ao longo da história do cinema americano, muitos médicos ou cientistas da área biológica utilizaram seus conhecimentos em suas incursões ao cinema, como é o caso de Michael Crichton, médico de profissão que se tomou um popular escritor de best-sellers médicos e dirigiu alguns filmes deles adaptados.. No caso por exemplo da Literatura, há quem pense que "Doctors as authors are able to achieve medical plausibility and avoid errors that many readers, especially the medically oriented, will spot" ${ }^{\prime 3}$ Este porém não é o paradigma prevalecente. O cinema se apropria livremente da Medicina e dos temas médicos como o faz com quaisquer outros, respeitando na medida dos interesses da narrativa e da fantasia (e também do 
mercado, naturalmente) as conveniências de uma exata representação do universo retratado. O público "medicamente informado" pode torcer o nariz diante de certas "licenças poéticas", mas em geral aceita que as convenções da fiç̧ão cinematográfica não sejam regidas por um respeito "documental" à realidade.

\section{Notas:}

1. A respeito dos temas do realismo e do verossímil no cinema, ver AUMONT, Jacques et al. Estética do cinema. Campinas: Papirus. 1995, p. 134 e 141. 2. McKAY, Susan. Beyond Biomedicine: Rencgotiating the Sick Role for Postmodern Conditions. In: Media Culture. Disponível em:

, acesso em outubro de 2001.

3. Morris, David. "How to Speak Postmodern: Medicine, Illness. and Cultural Change." The Hastings Center Report 30.6 (2000): 7-11; citado por MCKAY, Susan, op. cit.

4. HOGLE, Linda F. "Tales from the Cryptic: Technology Meets Organism in the Living Cadaver," Cyborg Handbook, 203.

5. Em relação a Vertigo, Totaro diz que Kim Novak parece estar interpretando dois papéis separados, mas "de fato é a mesma pessoa atuando em una farsa"; na verdade, Kim Novak interpreta três papéis, dois recais - a verdadeira Madeleine, de quem só vemos o cadáver numa seqüência de flashback na torre do campanário - e Judy Barton; e um ilusório, a falsa Madeleine da primeira parte do filme, que é o "duplo" de Judy Barton. 6. Em sua autobiografia Meu último suspiro, Buñucl esclareceu que o uso de duas atrizes diferentes não foi uma idéia inicial, mas uma contingência pelo fato de ele ter brigado antes do final das filmagens com a espanhola Angela Molina.

7. FACE/OFF. Entrevista de Michael Colleary e Mike Werb. Written By, agosto 1997. Disponível em , acesso em outubro de 2001.

8. Um exemplo curioso de relação entre Cinema e Medicina em Hollywood é o fato de que o especialista Rick Lazzarini, dono da empresa de animatronics The Character Shop e reponsável pela fabricação das máscaras, próteses e criaturas de filmes como Aliens - O Resgate e cemtenas de outros, se associou em 1994 à EndoCare, um famoso centro cirúrgico de Los Angeles, para fabricar modelos plásticos de órgãos humanos internos para auxiliar o treinamento em endoscopia. A iniciativa foi da própria EndoCare, convencida de que Lazzarini tinha a tecnologia ideal para produzir réplicas em silicone perfeitas de partes do corpo humano, 
como estômago, útero etc., que substituíram vantajosamente cadáveres e animais usados tradicionalmente no ensino de técnicas endoscópicas.

9. Um bom texto sobre o filme é o de PANAYIDES, Theodoros. His Kind of Woman. Agosto de 2000. In: Senses of Cinema, , acesso outubro 2001.

10. A este respeito, ver LEDERER, Susan E.

11. O título francês de Seconds é bastante sugestivo: L'opération diabolique.

Sobre o impacto da Cirurgia Plástica na Cultura Americana, veja-se o elogiado livro da historiadora Elizabeth Haiken, Venus Envy: a History of Cosmetic Surgery. Baltimorore, MD: The Johns Hopkins University Press, 1997.

12. PAULSCHOCK, Bernardine Z. [Resenha da novela Miracle Cure, de Michael Palmer, New York: Bantham Books, 1998]. In: JOURNAL OF AMERICAN MEDICAL ASSOCIATION, v. 280, n. 22, 9 dec 1998, p. 1962.

\section{BIBLIOGRAFIA:}

BAECQUE, Antoine de. Le lieu à l'oeuvre. Fragments 104 pour une histoire du corpos au cinéma. Vertigo, n. 15, 1996. Fragments pour une histoire du corps au cinéma. Vertigo, n. 15, 1996.

BONNER, F., \& S.McKay. "Challenges, Determination and Triumphs: Inspirational Discourse in Women's Magazine Health Stories." Continuum: Journal of Media and Cultural Studies 14.2 (2000): 133-144.

CHRISTOPOULOS, Katerina. "The Sick Role in Literature and Society." Journal of the American Medical Association 285.1 (3 January 2001): 93. COUSER, G. Thomas. Recovering Bodies: Illness, Disability, and Life Writing. Madison: University of Wisconsin Press, 1997.

COATES, Paul. The Story of the Lost Reflection. In: The New Left Review, Nr. 143, pp. 120-128.

CURTIS, Scott. "As Tangible as Tissue": Film and Medical Hermeneutics. Disponível em

acesso em outubro de 2001.

DANS, Peter E. Doctors in the Movies: Boil the Water and Just Say Aah. Bloomington, Illinois: Medi-Ed Press, 2000.

DUBOS, René. "Mirage of Health". Health and Disease. Ed. Nick Black. Milton Keynes: Open University Press, 1984. 4-9. 
EISENBERG, Leon, and Arthur Kleinman. "Clinical Social Science." The Relevance of Social Science for Medicine. Ed. Leon Eisenberg and Arthur Kleinman. Dordrecht: Reidel, 1981. 1-23.

ENGEL, George. "The Need for a New Medical Model: A Challenge for Biomedicine." Science 196.4268 (8 April 1977): 129-36.

FRANK, Arthur: "Reclaiming an Orphan Genre: The First-Person Narrative of Illness." Literature and Medicine 13.1 (Spring 1994): 1-21.

GABBARD, Glen O.; GABBARD, Krin. Psychiatry and the cinema. $2^{2}$ ed. Washington: American Psychiatric Press, 1999, 408 p.

GEORGE, Janet; DAVID, Alan. States of Health: Health and Illness in Australia. 3rd ed. South Melbourne: Addison Wesley Longman, 1998. HARDEY, Michael. "Doctor in the House: The Internet as a Source of Lay Knowledge and the Challenge to Expertise." Sociology' of Health and Illness 21.6 (1999): 820-835.

HAWKINS, Anne. Reconstructing Illness: Studies in Pathography. West Layfayette: Purdue University Press, 1993.

HOGLE, Linda F. "Tales from the Cryptic: Technology Meets Organism in the Living Cadaver," Cyborg Handbook, 203.

LUPTON, Deborah. Medicine as Culture: Illness, Disease and the Body in Western Societies. London: Sage, 1994.

MCKAY, Susan. Beyond Biomedicine: Renegotiating the Sick Role for Postmodern Conditions. Disponível em:

$$
\text { , agosto } 2001 .
$$

MORGAN, Myfanwy; CALNAN, Michael, MANNING; Nick. Sociological. Approaches to Health and Medicine. London: Routledge, 1985. MORRIS, David. "How to Speak Postmodern: Medicine, Illness. and Cultural Change." The Hastings Center Report 30.6 (2000): 7-11.

PATSOS, Mary. The Internet and Medicine: Building a Community for Patients with Rare Diseases. Journal of the American Medical Association 285.6 (14 February 2001): 805.

TOTARO, Donald. The Contemporary Doppelgänger. In: Hors Champ. Disponivel em: (

), 13 de fevereiro de 1998, acesso em outubro de 2001.

TURNEY, Jon. Frankenstein'S Footsteps. Science, Genetics and Popular Culture. Yale: University Press, 1998.

VIEIRA, João Luiz. "Anatomias do visível: cinema, corpo e cultura visual médica - uma introdução". In: RAMOS, Fernão (org.). Estudos de Cinema. Socine II e Ill. São Paulo: Annablume, 2000, pp. 80-5. 
106

Palavras-chave

1. cinema narrativo

2. Face/Off

3. paradigma biomédico 